\title{
Constructive Memory: Past and Future
}

\section{Citation}

Schacter, Daniel L. 2012. Constructive memory: past and future. Dialogues in Clinical Neuroscience 14(1): 7-18.

\section{Permanent link}

http://nrs.harvard.edu/urn-3:HUL.InstRepos:11210603

\section{Terms of Use}

This article was downloaded from Harvard University's DASH repository, and is made available under the terms and conditions applicable to Other Posted Material, as set forth at http:// nrs.harvard.edu/urn-3:HUL.InstRepos:dash.current.terms-of-use\#LAA

\section{Share Your Story}

The Harvard community has made this article openly available.

Please share how this access benefits you. Submit a story.

Accessibility 


\title{
State of the art
}

\section{Constructive memory: past and future}

\author{
Daniel L. Schacter, PhD
}

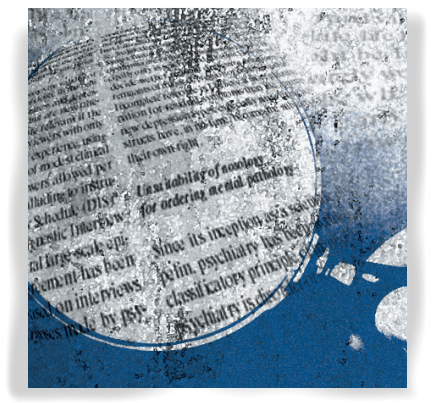

Human memory is not a literal reproduction of the past, but instead relies on constructive processes that are sometimes prone to error and distortion. Understanding of constructive memory has accelerated during recent years as a result of research that has linked together its cognitive and neural bases. This article focuses on three aspects of constructive memory that have been the target of recent research: (i) the idea that certain kinds of memory distortions reflect the operation of adaptive cognitive processes that contribute to the efficient functioning of memory; (ii) the role of a constructive memory system in imagining or simulating possible future events; and (iii) differences between true and false memories that have been revealed by functional neuroimaging techniques. The article delineates the theoretical implications of relevant research, and also considers some clinical and applied implications.

() 2012, LLS SAS

Dialogues Clin Neurosci. 2012;14:7-18.

Keywords: episodic memory; memory distortion; false memory; hippocampus, future thinking; episodic simulation; neuroimaging

Author affiliations: Department of Psychology, Harvard University, Cambridge, Massachusetts, USA

Address for correspondence: Daniel L. Schacter, Department of Psychology, Harvard University, Cambridge, Massachusetts 02138, USA (e-mail: dls@wjh.harvard.edu)

\author{
Introduction
}

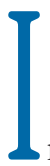

$\mathrm{n}$ an interview that took place some years ago at a hospital in Geneva, a 63-year-old female psychiatrist, Mrs B, recollected a pleasant visit earlier that day with her mother and brother. She also looked forward to a reception later in the day that she would be hosting at her home. Mrs B was utterly convinced that these events were real, but in fact they were not: Mrs B was herself a patient in the hospital, where she was recovering from a brain hemorrhage. Mrs B had confabulated these events, which had no basis in reality. ${ }^{1}$

While the disconnection between memory and objective reality that is evident in Mrs B's case is attributable to her brain damage, not all such disconnections reflect the influence of brain pathology; far from it. For example, memory and reality often conflict in eyewitness testimony, where different observers of the same event sometimes recollect that event in dramatically different ways. One striking but fairly typical example is provided by the death of Jean Charles de Menezes, an innocent man who was fatally shot in July 2005 by London police in a subway station, because he had been misidentified by them as one of several men responsible for a failed bombing attempt the previous day. Eyewitness accounts of what transpired differed substantially. ${ }^{2}$ While the officers "recalled running on to the Underground platform at Stockwell and challenging de Menezes by shouting 'Armed Police,' before shooting him seven times in the head," 17 civilian witnesses had no memory that this phrase had been uttered. The police claimed that de Menezes had gotten up and moved "aggressively" at them, but according to the memories of some witnesses, 


\section{State of the art}

de Menezes never got up from his seat. Indeed, "Everyone recalled a slightly different sequence of events, even when it came to such basic facts as the number of bullets fired or the clothes de Menezes was wearing." 2

While it is difficult to be certain whose memories are accurate and whose are not in such a case, it seems reasonably clear that some witnesses to the de Menezes shooting remembered it incorrectly. Such a conclusion is consistent with many controlled studies showing that eyewitnesses are prone to memory errors, including highly confident but demonstrably false memories. ${ }^{3.5}$ These faulty memories can have serious consequences: inaccurate eyewitness testimony was a key factor in approximately $75 \%$ of the first hundred cases of individuals exonerated by DNA evidence after being convicted of crimes they did not commit. ${ }^{6,7}$

These and related observations lend support to a view of memory that has its roots in the work of the British psychologist Bartlett, ${ }^{8}$ who argued, based on his experimental observations of mistakes and distortions in the recall of stories, that human memory is not a simple rote or reproductive system. By contrast, memory involves complex constructive processes that are sometimes prone to error: when we remember, we piece together fragments of stored information under the influence of our current knowledge, attitudes, and beliefs.

A good deal of progress has been made in understanding the constructive nature of memory since the publication of Bartlett's ${ }^{8}$ classic studies. That progress has begun to accelerate during recent years, as a result of research using the methods of cognitive psychology and cognitive neuroscience to elucidate both the cognitive and neural processes that underpin constructive memory. ${ }^{9-13}$ The purpose of the present paper is to consider recent ideas and evidence concerning three aspects of constructive memory for which significant new findings and ideas have emerged during the past few years. First, the article will consider the idea that certain kinds of memory distortions reflect the operation of adaptive cognitive processes - that is, processes that contribute to the efficient functioning of memory, but as a result of doing so, also produce distortions. ${ }^{14-17}$ Second, it will focus on recent research that is beginning to elucidate the nature of an adaptive cognitive process that has been linked to constructive memory: imagining or simulating possible future events. ${ }^{18,19}$ Third, it will consider whether it is possible to reliably distinguish between true and false mem- ories, and discuss some recent attempts to do so using functional neuroimaging techniques.

\section{Are memory distortions adaptive?}

Clinical instances of confabulation following brain damage, such as the case of Mrs B considered earlier, encourage the view that memory distortion reflects dysfunctional cognitive processing. And, indeed, it is known that various kinds of brain damage can result in an increased incidence of memory distortion. For example, during the 1990s Schacter et al studied a patient, BG, who suffered damage to his right frontal lobe after a stroke. ${ }^{20,21}$ BG showed a dramatic increase in the incidence of a memory error known as false recognition, where one claims to recognize as familiar an object, face, word, or scene that is in fact novel. Across a range of memory tests, BG falsely recognized - with high confidence-various kinds of novel stimuli. More recently, Moulin et $\mathrm{al}^{22}$ described a related syndrome in cases of dementia and diffuse temporal lobe pathology, that they termed déjà vecu, where patients claim to recollect past "experiences" that are actually novel. For example, patient AKP constantly stopped watching television because he claimed to remember seeing every show previously, and when going on a daily walk, "AKP complained that it was the same bird in the same tree singing the same song... He also read car number plates and stated that the drivers must have very regular habits, always passing by at the exact same time every day." 22 Links between memory distortion and dysfunctional processing have also been made in healthy, non-braindamaged individuals. Several studies have found that individuals who frequently report disruptions in consciousness or dissociative experiences also tend to show increased rates of false recognition and related memory distortions. ${ }^{23-26}$ More recent research has linked propensity to memory distortion with low intelligence ${ }^{27}$ and symptoms of post-traumatic stress disorder. ${ }^{28}$ Based on these kinds of observations, it seems justified to conclude that memory errors and distortions, and the constructive memory processes that give rise to them, reflect deficient processing and perhaps fundamental flaws in the architecture of the memory system.

In contrast to this line of reasoning, there is mounting evidence that several different kinds of memory distortions reflect the influence of adaptive processes that are beneficial for cognitive function, but nonetheless also 
result in memory errors. ${ }^{15}$ This line of argument can be traced to the classic studies of Bartlett, ${ }^{8}$ who took what could be characterized as an adaptive view when discussing the memory distortions that he observed during recall of stories. Bartlett believed that these distortions were based on the operation of a schema that serves to organize and interpret incoming information in light of previous experiences. My own writing about the seven "sins" of memory, ${ }^{16,17}$ has tried to make the case that each of the seven sins reflect, to some extent, the operation of adaptive cognitive processes. However, while these and related arguments ${ }^{9,14}$ are plausible, there has been relatively little direct experimental data in support of them until the past few years. As an example, let us consider evidence that has accumulated for the adaptive nature of what are called gist-based or associative memory distortions. $^{15}$

Gist-based and associative memory errors are closely related. Gist-based errors occur when people falsely remember a novel item that is similar to an item that they encountered previously, making their memory decision based on the gist of what happened, whereas associative memory errors occur when people falsely remember a novel item that is an associate of previously studied items. Understanding of these kinds of memory distortions has been advanced by studies using the "DRM paradigm," which was developed initially by Deese, ${ }^{29}$ and later modified by Roediger and McDermott. ${ }^{30}$ In this procedure, participants hear or view lists of related words (eg, candy, sour, sugar, bitter, good, taste, tooth, etc) that are all associates of a nonpresented "critical lure" word (eg, sweet). Numerous studies have shown that participants often falsely recall or recognize the nonpresented associates, and do so with high confidence..$^{31,32}$ Researchers have used related paradigms for producing gist-based memory errors. For example, after studying patterns or shapes that are physically similar to a nonpresented prototype, participants later are likely to falsely recognize the novel prototype as a previously studied item. ${ }^{33,34}$ Similarly, after studying numerous pictures or words from a particular category, people are likely to later show false recall or false recognition of nonpresented category members from the previously presented categories. ${ }^{35,36}$

While such responses are classified appropriately as memory distortions-people claim to remember items that they have never encountered before-those errors also reflect retention of useful information concerning the general themes, appearances, or meanings that participants did encounter. Retention of such information can facilitate the ability to generalize and abstract, $, 16,17,37,38$ and in that sense can be considered adaptive.

Several kinds of experimental evidence support the idea that gist-based and associative memory errors indeed reflect the operation of adaptive processes. First, both associative and gist-based false recognition are reduced in patients with amnesic syndromes resulting from damage to the medial temporal lobes, thereby suggesting that such errors normally reflect the operation of a healthy memory system..$^{39-41}$ Second, recent studies have linked associative false recognition and creativity. In one study study, Howe et $\mathrm{al}^{42}$ presented DRM associate lists to children and adults before these participants attempted to solve compound remote associate task problems. Participants were presented with three word puzzles (eg, walk/beauty/over) and attempted to generate a solution word that is associated with all three target words (eg, sleep). When they were primed with DRM lists (eg, bed, rest, awake, tired, dream, etc) for which the solution word on the problem-solving task was the critical lure (eg, sleep), both children and adults showed improved performance on the problem-solving tasks compared with problems that were not primed by DRM lists. Importantly, however, this effect was observed only when participants falsely recalled the critical lure, thereby bolstering the authors' claim that false memories can have beneficial effects on cognitive function under certain conditions. In another recent study linking creativity and associative false recognition, Dewhurst et $\mathrm{al}^{43}$ showed that susceptibility to DRM false recognition is predicted by performance on a remote associates task. This task is generally viewed as a measure of convergent thinking - a component of creativity that taps an individual's ability to generate broad and numerous associations, and can thus be considered an adaptive cognitive process. By contrast, DRM false recognition was not predicted by performance on a task that required generating alternate uses of an object, which is thought to tap divergent thinking (ie, the capacity to generate a range of different possible solutions to a problem).

Third, a growing number of neuroimaging studies have documented that many of the same brain regions are active during associative/gist-based true and false recognition. ${ }^{34,44-47}$ Consistent with the foregoing studies, GaroffEaton et $\mathrm{al}^{48}$ observed extensive overlap in neural activity when participants made false recognition responses 


\section{State of the art}

to shapes that were visually similar to those that they had studied (ie, during gist-based false recognition). In contrast, there was no neural overlap between true and false recognition when participants had false alarms to novel shapes that were unrelated to previously studied shapes, which likely reflected guessing, or other processes that did not reflect gist-based responding. Thus, gist-based false recognition, but not unrelated or "baseline" false recognition, recruits the same regions that are associated with true recognition.

Fourth, neuroimaging studies that have examined the origins of gist-based or associative false recognition during the process of encoding have likewise provided evidence in line with an adaptive interpretation. For example, it has been demonstrated that levels of gist-based false recognition of new words from previously studied categories are associated with increased activation of left ventrolateral prefrontal cortex during encoding of categorized words ${ }^{49,50}$; similar findings have been obtained when participants encode common objects and later falsely recognize new objects from the same category. ${ }^{51}$ Critically, these studies also showed that recruitment of left ventrolateral prefrontal cortex is associated with increased subsequent true recognition and earlier work linked this region with semantic or elaborative encoding processes. ${ }^{52}$ Taken together, the foregoing findings provide an empirical basis for arguing that semantic elaboration processes during encoding, which serve the adaptive function of promoting long-term retention, can also contribute to memory distortion.

Finally, a closely related line of evidence comes from a recent fMRI study that applied the same kind of encoding-based analysis described in the aforementioned studies to false recognition of contextual associations. Aminoff et $\mathrm{al}^{53}$ had participants encode a series of object pairs while in the scanner by trying to mentally relate the objects to a context.

The pairs consisted of either two contextually related objects that belong to the same context, such as a bulldozer and a yellow construction cone, or two objects that are typically not associated with a specific context or contextually related to each other, such as a camera and a pair of scissors. The next day, participants were given an old/new recognition test that included previously studied objects, unrelated new objects, and, critically, new objects that were contextually related to one of the previously studied context pairs (eg, a construction helmet). We hypothesized that increased activity during encod- ing in cortical regions previously identified as part of a network that supports contextual processing ${ }^{54,55}$ would predict subsequent false recognition of contextually related objects, and the results supported this hypothesis. Perhaps most important from an adaptive perspective, encoding-related activity in the retrosplenial complex predicted subsequent false recognition of contextually related objects. Bar and Aminoff ${ }^{54}$ have theorized that this region is involved in the processing of "context frames," which represent generic or prototypical information about a context. Activation of a context frame during encoding is adaptive because it can facilitate recognition of other objects in the environment by allowing predictions about what is likely to occur in a particular context. ${ }^{56}$

These studies provide compelling evidence favoring an adaptive account of gist-based and associative errors. Schacter et a $1^{15}$ also discussed additional evidence and ideas that point toward an adaptive interpretation for other kinds of memory distortions, including post-event misinformation effects ${ }^{10}$ and imagination inflation, ${ }^{57-59}$ where imagining events can lead to false beliefs and memories that they did occur. Our adaptive account of imagination inflation relied heavily on recent observations concerning the role of a constructive memory system in imagining future events, which will be discussed in the next section of the paper.

\section{Constructive memory and imagining the future}

Numerous experiments have demonstrated ways in which imagining events can lead to the development of false memories for those events..$^{57-64}$ During the past several years, neuroimaging studies have revealed striking overlap in the neural processes that are engaged when people remember past events and imagine future events or novel scenes, ${ }^{65-70}$ and behavioral studies have documented similarly striking similarities in the corresponding cognitive processes. ${ }^{18,19,71-79}$ The similarities documented in these studies can help to understand why memory and imagination can be easily confused: they share common neural and cognitive underpinnings. In addition, we have argued that these observations are relevant to thinking about the adaptive functions of a constructive memory system. Specifically, Schacter and Addis ${ }^{18}$ have put forward the constructive episodic simulation hypothesis, which holds that past and future events 
draw on similar information stored in memory (episodic memory in particular) and rely on similar underlying processes. Episodic memory, in turns, supports the construction of future events by extracting and recombining stored information into a simulation of a novel event. Such a system is adaptive because it enables past information to be used flexibly in simulating alternative future scenarios without engaging in actual behaviors, but it comes at a cost of vulnerability to errors and distortions that result from mistakenly combining elements of imagination and memory.

One of the most intriguing findings from neuroimaging studies that is relevant to the constructive episodic simulation hypothesis concerns the robust activation of the hippocampus - a region that has long been implicated in memory - when individuals imagine or simulate future events. Consider, for example, a study by Addis et $\mathrm{a}^{65}$ in which participants were scanned while they were either remembering a past experience or imagining an event that might occur in the future. Addis et al divided each of these tasks into two phases. In the initial construction phase, participants generated either a remembered or an imagined event in response to a cue word (eg, "dress") and made a button-press when they had an event in mind, which typically required about 7 or 8 seconds. In the immediately following elaboration phase, participants generated as much detail as possible about the remembered or imagined event. The most striking finding was that brain activity was highly similar during remembering the past and imagining the future. This overlap was most apparent during the elaboration phase, when participants focused on generating details about the remembered or imagined event. A core network ${ }^{77}$ of brain regions that had previously been implicated in the retrieval of episodic memories, and has also been linked to a variety of internally driven cognitive processes, ${ }^{80,81}$ showed common activation during both remembering and imagining, including the hippocampus, parahippocampal and retrosplenial cortices, medial prefrontal and frontopolar cortices, and lateral parietal lobe.

The common activation observed in the hippocampus was especially intriguing, possibly reflecting the retrieval or integration of event details into the remembered or imagined representation. Moreover, during the construction phase, the right hippocampus was engaged to a greater extent when participants imagined future events than when they remembered past events. Because the hippocampus has been implicated in relational pro- cessing (ie, linking together previously unrelated items $^{82}$ ), Addis et al suggested that this finding might reflect the additional relational processing required when one recombines disparate details into an imagined future event. ${ }^{18,83,84}$

Following up on the foregoing findings with respect to hippocampal activity, Addis and Schacter ${ }^{85}$ examined the relationship between brain activity and the amount of detail reported for remembered and imagined events during the elaboration phase. Addis and Schacter observed that activity in the left posterior hippocampus was correlated with the amount of detail comprising both remembered and imagined events, whereas the left anterior hippocampus responded specifically to the amount of detail comprising imagined but not remembered events. In line with the previous discussion, Addis and Schacter suggested that this latter finding could reflect activity associated with the recombination of details into an imagined future event.

More direct evidence on this point is provided by a study that made use of a novel experimental recombination paradigm.${ }^{86}$ Participants initially provided episodic memories of actual experiences that included details about a person, object, and place involved in that event. During a later scanning session, they were cued to recall some of the events that had actually occurred. For the conditions in which they imagined events, the experimenters randomly recombined details concerning person, object, and place from separate episodes. Then, during scanning, participants were given cues for a person, object, and place taken from distinct episodes, and were instructed to imagine a single, novel episode that included the specified details. In some cases, participants were instructed to imagine possible future events, whereas in others, they were instructed to imagine events that might have occurred in the past. As in previous studies, robust hippocampal activity was observed when participants recombined details into an imaginary scenario.

While these findings are consistent with a role for the hippocampus in recombining episodic details, Martin et al have recently examined whether the hippocampus also plays a role in a closely related process: encoding recombined details into memory. Several decades ago, Ingvar ${ }^{88}$ developed an idea that he called "memory of the future": when we simulate an upcoming future scenario, we need to encode and store that simulation for later use in order to maximize its adaptive effect on future behavior. Although next to nothing is known about the neural 


\section{State of the art}

processes that support "memory of the future," Martin et $\mathrm{al}^{87}$ hypothesized a role for the hippocampus. To investigate the issue, we examined whether hippocampal activity during simulations of future experiences is related to memory for those simulations by using the experimental recombination paradigm described earlier ${ }^{86}$ together with the well-established "subsequent memory" procedure, where brain activity during encoding is related to whether an item is later remembered or forgotten on a memory test. The subsequent memory procedure has been used successfully in numerous previous studies on the neural correlates of encoding processes. ${ }^{89,90}$

During scanning, participants imagined future events comprised of recombined person, location, and object details that were taken from their own memories provided in a prescanning session. A few minutes after completion of the scan, participants were given an unexpected cued recall test that probed memory of their simulation: they were provided with two details from the simulation and were instructed to recall the third detail. Simulations for which participants provided the missing detail were classified as "remembered," and those for which participants did not provide the correct missing detail were classified as "forgotten," thereby providing an objective measure of whether the details from each simulation had been successfully encoded.

Results showed that the core network identified in previous studies, including the hippocampus, was active

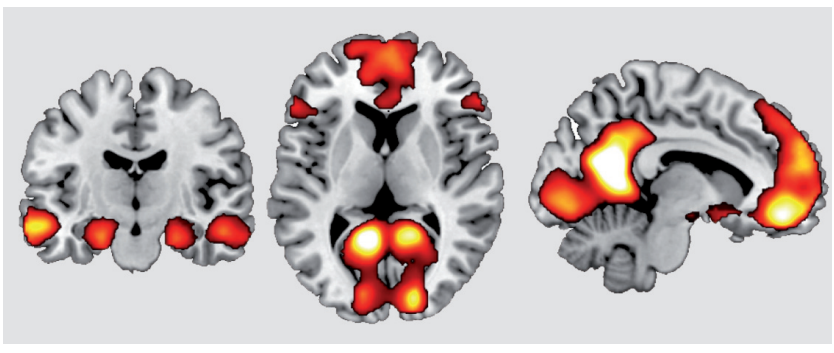

Figure 1. Regions of a core network engaged by imagining future events. In a recent study described in the text, ${ }^{87}$ participants imagined future events including person, place, and object details that were taken from actual memories. On control trials, participants created a "size sentence," ordering three objects by physical size. The contrast of future events relative to control trials revealed significant activation of a core network identified in other similar studies, including bilateral medial parietal and prefrontal cortices (right and middle) and bilateral medial temporal lobes and left lateral temporal cortex (left).

Adapted from ref 87: Martin VC, Schacter DL, Corballis MC, Addis DR. A role for the hippocampus in encoding simulations of future events. Proc Natl Acad Sci U S A. 2011;108:13858-13863. Copyright @ National Academy of Sciences 2011 when participants imagined future events (Figure 1). Critically, we also found that simulations classified as "remembered" based on subsequent recall performance were associated with greater activity in right hippocampus at the time of encoding than were simulations that were classified as "forgotten" (Figure 2). Further, we found that participants rated the successfully remembered simulations as more detailed than simulations that were subsequently forgotten, and that activation in brain regions that showed an encoding effect was modulated by the level of detail. These observations suggest that constructing a lasting "memory for the future" is related to how well details comprising a simulation were retrieved from memory and recombined during encoding.

In a related line of research on another aspect of "memory of the future," Szpunar et $\mathrm{al}^{91}$ have examined how well individuals remember simulations of positive, negative, or neutral simulations of possible future events. Episodic simulations typically refer to emotionally arousing events: recent evidence indicates that roughly two thirds of thoughts about everyday future events are

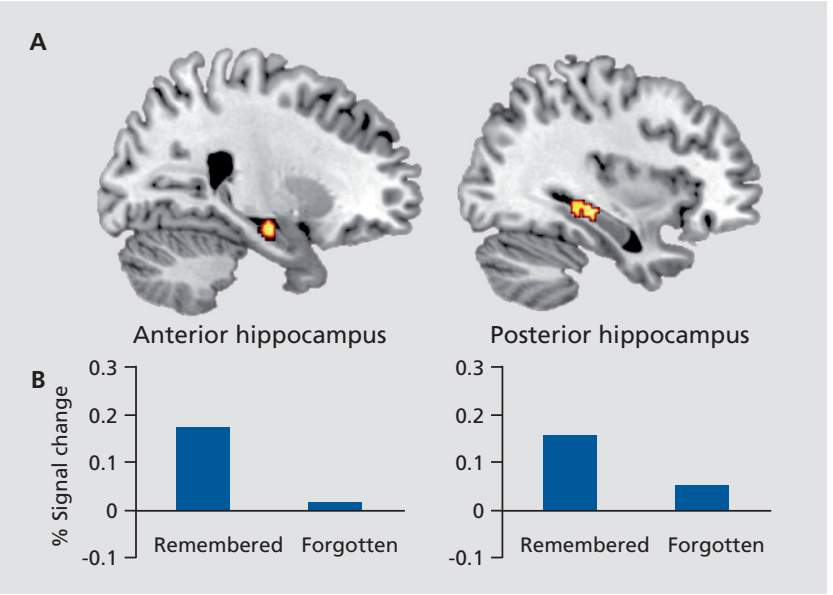

Figure 2. Hippocampal responses to encoding. In the same study described in Figure $1,{ }^{87}$ approximately 10 minutes after imagining future events comprised of person, place, and object details, participants were given a cued recall test in which two details from the simulation were provided, and they were asked to recall the third detail. A subsequent memory analysis revealed clusters in anterior and posterior right hippocampus that showed significantly greater activity during encoding for those simulations in which details were subsequently remembered vs those in which details were subsequently forgotten.

Adapted from ref 87: Martin VC, Schacter DL, Corballis MC, Addis DR. A role for the hippocampus in encoding simulations of future events. Proc Natl Acad Sci U S A. 2011;108:13858-13863. Copyright @ National Academy of Sciences 2011. 
either positively or negatively charged. ${ }^{92}$ To investigate memory for such simulations, we used a variant of the experimental recombination-subsequent memory procedure used by Martin et $\mathrm{al}^{87}$ in the previously described study in which participants imagined future events comprised of recombined person, location, and object details. Each recombined set of details was presented along with one of three emotional tags-either positive, negative, or neutral. On each trial, participants were instructed to generate a plausible future event that might occur within the next 5 years and that would evoke in them the emotion indicated by the emotional tag. Memory was tested either after a 10-minute delay or a 1-day delay using the cued recall procedure described above, ie, participants were provided with two details from the simulation and were instructed to recall the third detail (no scanning was performed in this experiment).

After the 10-minute delay, recall of details associated with positive and negative simulations was significantly greater than recall of details associated with neutral simulations - a finding that is consistent with a large body of literature indicating that memory for emotional experiences is typically enhanced compared with memory for neutral experiences. ${ }^{93,94}$ Strikingly, however, at the 1-day delay, the details associated with negative simulations were remembered significantly less often than the details associated with positive and neutral simulations.

We related this finding to previous studies that have documented a phenomenon known as "fading affect bias": emotional reactions tend to fade more quickly over time for negative than positive everyday experiences. ${ }^{95}$ Perhaps rapid fading of negative affect over time rendered details associated with negative simulations more difficult to recall than those associated with positive or neutral simulations. Although additional research will be required to understand this finding, it may be related in interesting ways to the simulation of future events in clinical populations with affective disorders. A number of studies have shown that patients with depression ${ }^{96,97}$ and anxiety ${ }^{98,99}$ exhibit impaired simulations of future events that tend to lack specific detail and are often negatively biased. These observations, as well as related observations of impaired future simulations in other psychiatric and neurological disorders (for reviews, see refs 19,78), highlight the clinical relevance of research concerning imagining the future. They also suggest that it will be interesting to examine memory for positive and negative simulations in depressed and anxious patients in order to determine whether patterns consistent with "fading affect bias"-ie, impaired recall of negative simulations after a long delay versus a short delay-are absent or reduced in such patients.

\section{Distinguishing between true and false memories}

The observation that memory and imagination depend, at least in part, on a common neural network, raises an important question: how does the brain distinguish between memories for actual past experiences and those that have only been imagined? One clue comes from the Addis et a ${ }^{86}$ study discussed earlier, in which participants were scanned while remembering actual events consisting of key person-place-object details, or imagining experiences comprised of recombined details from different memories. As in previous studies, the core network discussed earlier was activated for both remembering and imagining. In addition, however, Addis et $\mathrm{al}^{86}$ noted that distinct subsystems within the core network were preferentially associated with imagining and remembering, respectively. The imagining network consisted of medial temporal lobe including anterior hippocampus, bilateral medial prefrontal cortex, inferior frontal gyrus, polar and posterior temporal cortex, and medial parietal cortex. The remembering network included posterior visual cortices such as fusiform, lingual and occipital gyri and cuneus, as well as parahippocampal gyrus and posterior hippocampus. Addis et $\mathrm{al}^{86}$ suggested that the association of posterior visual cortices with memory for actual experiences might indicate that reactivation of sensory-perceptual details during memory retrieval recruits the neural regions involved in the original processing of the remembered information. Consistent with this suggestion, neuroimaging studies of memory for previously studied pictures have revealed reactivation during retrieval of some of the same visual processing regions that were active during encoding. ${ }^{100}$

These observations dovetail nicely with an idea initially advanced by cognitive psychologists, often referred to as the sensory reactivation hypothesis, that true memories tend to contain more sensory and perceptual information than do false memories. ${ }^{62,101}$ Consistent with this hypothesis, behavioral studies have shown that retrieval of true memories is associated with increased access to sensory and perceptual details compared with retrieval of false or imaginary memories. ${ }^{101-105}$ 


\section{State of the art}

More recently, neuroimaging studies in which participants are scanned during retrieval of true and false memories have provided additional evidence consistent with the sensory reactivation hypothesis. For example, in several neuroimaging studies using the DRM semantic associates paradigm, participants who were scanned during retrieval showed increased activity in sensory-perceptual regions during true recognition as compared with false recognition. ${ }^{44-46}$ However, whether or not such effects are observed may depend on subtle features of the experimental design. . $^{13,47,106}$

In an attempt to examine sensory reactivation effects using material known to engage perceptual processing pathways, Slotnick and Schacter ${ }^{34}$ used novel visual shapes as target stimuli. All the shapes that participants studied were physically similar to prototype shapes that were not presented during encoding. Following presentation of the study list, participants made old/new recognition decisions about previously studied shapes, nonstudied related shapes, and nonstudied unrelated shapes. Slotnick and Schacter ${ }^{34}$ hypothesized that true recognition of previously studied shapes, as compared with false recognition of nonstudied related shapes, would be accompanied by a sensory signature involving increased activation of visual processing regions. Consistent with this hypothesis, there was significantly greater activity during true than false recognition in regions of primary visual cortex (eg, BA 17,18) that are concerned with processing such features of target stimuli as orientation and color. By contrast, higher-order visual areas in occipito-temporal cortex (eg, BA 19, 37) showed comparable levels of activity during true and false recognition.

Consistent with the foregoing, additional evidence supporting the sensory reactivation hypothesis has been reported in studies using fMRI to examine the widely known post-event misinformation effect. ${ }^{10}$ In misinformation studies, participants are exposed to an original event consisting of a sequence of activities, and are later given inaccurate information about some aspect of the original event; on a subsequent memory test, participants sometimes falsely remember that the post-event misinformation was part of the original event. In the first fMRI study of the misinformation effect, Okado and Stark ${ }^{107}$ scanned participants while they viewed vignettes (ie, event sequences) that each contained a critical detail (eg, in one vignette, a man puts a stolen wallet in his jacket pocket), and also during the post-event misinformation phase, when participants were exposed to erro- neous information about what had happened in the original event (eg, the man put the stolen wallet in his pants pocket). Two days later, participants were given a memory test including both events that occurred in the original vignette and those that appeared only in the misinformation phase. Okado and Stark ${ }^{107}$ found that the occurrence of the misinformation effect- ie, when participants claimed that a bit of misinformation was part of the initial vignette-was predicted by level of activity in the medial temporal lobe during encoding of both the original event and the misinformation.

In a twist on this paradigm designed to examine the role of sensory reactivation in the aforementioned effects, Stark et al had participants view vignettes similar to those used in the Okado and Stark ${ }^{107}$ study. The next day, during the misinformation phase, participants listened to a series of sentences; most of them accurately described what had occurred in the vignette that the participant viewed the previous day, but some contained misinformation. Fifteen minutes later, participants were scanned while they took a memory test that included items from the original vignette and the misinformation phase. Thus, true memories-items from the vignette that participants accurately claimed that they saw in the first phase-were based on prior visual experience (ie, viewing the vignettes). By contrast, false memories-items from the misinformation phase that participants inaccurately claimed that they saw in the first phase-were based on auditory information acquired during the misinformation phase. Stark et al found that true memories were associated with greater activity in visual cortex than were false memories (which were associated with activity in auditory cortex), thereby providing further support for the sensory reactivation hypothesis. Indeed, Stark et al ${ }^{108}$ noted that true recognition was preferentially associated with activity in early or primary regions of the visual cortex, thereby supporting and extending the results of Slotnick and Schacter ${ }^{34}$ in a very different kind of experimental paradigm (see also ref 109).

\section{Concluding comments}

The research reviewed here indicates that we are beginning to establish a neurocognitive foundation for understanding the kinds of constructive memory processes that have been documented and investigated by numerous cognitive psychologists dating back to the pioneering studies of Bartlett. ${ }^{8}$ This research provides evidence 
in support of claims that memory distortions often reflect the operation of adaptive processes, that an important function of a constructive memory is allowing individuals to flexibly use past experiences to simulate possible future events, and that sensory reactivation can help to distinguish true from false memories.

While the theoretical implications of research on constructive memory are important, as noted earlier in the article this research also has clinical and applied implications. Research on memory distortion, for example, played an important role in informing and shaping the debate over the accuracy of recovered memories of childhood sexual abuse that raged for over a decade during the 1990s and 2000s. ${ }^{110,111}$ Demonstrations that imagining events that never happened can sometimes produce false memories for those events ${ }^{59,112}$ alerted both researchers and clinicians to the possible dangers of encouraging patients in psychotherapy to imagine childhood experiences that might or might not have occurred. And, indeed, recent research indicates that there are good reasons to doubt the accuracy of memories of sexual abuse recovered during psychotherapy (in contrast to memories recovered outside of a therapeutic context, which tend to be accurate). ${ }^{111}$

Research on constructive memory is also relevant understanding inaccuracies in eyewitness memory, which are all too often implicated in wrongful convictions of innocent individuals. ${ }^{4,5}$ One frequently posed question concerns whether it is possible to distinguish between accurate and inaccurate eyewitness memories, perhaps by using neuroimaging techniques. Although, as discussed earlier, there are both cognitive and neural differences between true and false memories, it is not at all clear that those differences can be reliably detected in individual cases, as required in the courtroom: most studies that have used neuroimaging to distinguish true and false memories have done so by averaging across subjects and groups. ${ }^{113}$ Some recent evidence indicates that neuroimaging can be used to gain insights into the subjective experience of remembering in an individual subject on a single trial. Using a classification technique known as multivoxel pattern analysis, researchers were able to use a pattern classifier to accurately detect when individuals believed that they were remembering a specific event, regardless of whether the event had actually occurred. ${ }^{114}$ However, the pattern classifier could not reliably determine the objective status of memory for single events, that is, whether the rememberer's belief about the event was accurate - a failure that would clearly limit its applicability in the courtroom, at least for now. Other limitations of current research include the fact that laboratory studies have typically used college students as participants, whereas a much more diverse set of individuals are involved in real-world cases of eyewitness memory, and have also tended to use materials, such as word lists or pictures of shapes and objects, that may have limited application to everyday experiences. ${ }^{115}$

Interestingly, recent work using structural imaging has revealed that individual differences in reality monitoring ability-ie, the capacity to distinguish whether a previously encountered item came from an internal or external source-are linked to structural differences across individuals in the volume of the paracingulate sulcus within the medial anterior prefrontal cortex, a region that was previously linked to reality monitoring performance in functional neuroimaging studies. ${ }^{116}$ It should be useful to examine in future research whether information from structural imaging can be combined with functional neuroimaging data to improve discrimination between true and false memories in individual cases.

In light of the foregoing considerations and the material discussed earlier, it is clear that research on constructive memory can help to address some major theoretical questions concerning the nature and function of memory, as well as key applied issues that have important clinical and everyday consequences. Much work remains to be done in order to deepen our understanding of the neural basis and cognitive properties of constructive memory. But it seems clear that attempting to understand constructive memory processes by integrating perspectives from cognitive psychology and neuroscience has proven to be a productive approach in recent years, and there is every reason to believe that such an approach will continue to pay dividends in the future. $\square$

Acknowledgements: Preparation of this chapter was supported by NIMH MH060941. I thank Clifford Robbins for help with preparation of the manuscript. 


\section{State of the art}

\section{Memoria constructiva: pasado y futuro}

La memoria humana no es una reproducción literal del pasado, sino que se basa en procesos constructivos que algunas veces tienden al error $y$ la distorsión. La comprensión de la memoria constructiva ha avanzado durante los últimos años como resultado de la investigación que ha relacionado sus bases cognitivas y neurales. Este artículo se enfoca en tres aspectos de la memoria constructiva que han sido objetivos de la investigación reciente: 1) la idea que ciertos tipos de distorsiones de memoria reflejan cómo operan los procesos cognitivos de adaptación que contribuyen al eficiente funcionamiento de la memoria, 2) el papel del sistema de memoria constructiva en la imaginación o simulación de posibles eventos futuros y 3) las diferencias entre memorias verdaderas y falsas, las que han sido evidenciadas por técnicas de neuroimágenes funcionales. Este artículo bosqueja las sugerencias teóricas de la investigación más importante y también considera algunas consecuencias clínicas y aplicadas.

\section{Mémoire constructive : passée et future}

La mémoire humaine n'est pas une reproduction littérale du passé ; elle est plutôt fondée sur des processus constructifs parfois susceptibles d'erreurs et de distorsion. La compréhension de la mémoire constructive s'est accélérée ces dernières années grâce à la recherche qui a établi un lien entre ses bases cognitives et neurales. Cet article s'intéresse aux trois aspects de la mémoire constructive qui ont fait l'objet de recherches récentes : 1) l'idée que certains types de distorsion mnésique reflètent l'effet de processus cognitifs adaptatifs qui contribuent à un fonctionnement efficient de la mémoire ; 2) le rôle d'un système de mémoire constructive dans l'imagination ou la simulation des événements futurs possibles; 3) et des différences entre les mémoires vraie et fausse révélées par des techniques de neuro-imagerie fonctionnelle. Cet article décrit les implications théoriques d'une recherche pertinente, et présente également quelques implications cliniques et appliquées.

\section{REFERENCES}

1. Schnider A. The Confabulating Mind. Oxford, UK: Oxford University Press; 2008.

2. O'Connell S. The perils of relying on memory in court. The Telegraph. Dec 15, 2008.

3. Loftus EF. Eyewitness Testimony. Cambridge, MA: Harvard University Press; 1979.

4. Semmler C, Brewer N. Eyewitness memory. In: Brown J, Campbell $\mathrm{E}_{\mathrm{i}}$ eds. The Cambridge Handbook of Forensic Psychology. Cambridge, UK: Cambridge University Press; 2010:49-57.

5. Wells GL, Olson EA. Eyewitness testimony. Annu Rev Psychol. 2003;54:277-295.

6. Scheck B, Neufeld P, Dwyer J. Actual Innocence: Five days to Execution and Other Dispatches From the Wrongly Convicted. New York, NY: Doubleday; 2000. 7. Wells GL, Small M, Penrod S, Malpass RS, Fulero SM, Brimacombe CAE. Eyewitness identification procedures: recommendations for lineups and photospreads. Law Hum Behav. 1998;22:603-647.

8. Bartlett FC. Remembering. Cambridge, UK: Cambridge University Press; 1932.

9. Brainerd CJ, Reyna VF. The Science of False Memory. New York, NY: Oxford University Press; 2005.

10. Loftus EF. Planting misinformation in the human mind: a 30-year investigation of the malleability of memory. Learn Mem. 2005;12:361-366. 11. Mitchell KJ, Johnson MK. Source monitoring 15 years later: what have we learned from fMRI about the neural mechanisms of source memory? Psychol Bull. 2009;135:638-677.

12. Schacter DL, Norman KA, Koutstaal W. The cognitive neuroscience of constructive memory. Annu Rev Psychol. 1998;49:289-318.

13. Schacter DL, Slotnick SD. The cognitive neuroscience of memory distortion. Neuron. 2004;44:149-160.

14. Newman EJ, Lindsay SD. False memories: what the hell are they for? Appl Cogn Psychol. 2009;23:1105-1121.
15. Schacter DL, Guerin SA, St Jacques PL. Memory distortion: an adaptive perspective. Trends Cogn Sci. 2011;15:467-474.

16. Schacter DL. The Seven Sins of Memory: How the Mind Forgets and Remembers. Boston, MA: Houghton Mifflin; 2001.

17. Schacter DL. The seven sins of memory: insights from psychology and cognitive neuroscience. Am Psychol. 1999;54:182-203.

18. Schacter DL, Addis DR. The cognitive neuroscience of constructive memory: Remembering the past and imagining the future. Phil Trans $R$ Soc Lond B. 2007;362:773-786.

19. Szpunar KK. Episodic future thought: an emerging concept. Perspect Psychol Sci. 2010;5:142-162.

20. Curran T, Schacter DL, Norman KA, Galluccio L. False recognition after a right frontal lobe infarction: Memory for general and specific information. Neuropsychologia. 1997;35:1035-1049.

21. Schacter DL, Curran T, Galluccio L, Milberg W, Bates J. False recognition and the right frontal lobe: a case study. Neuropsychologia. 1996;34:793-808. 22. Moulin CJ, Conway MA, Thompson RG, James N, Jones RW. Disordered memory awareness: recollective confabulation in two cases of persistent déjà vecu. Neuropsychologia. 2005;43:1362-1378.

23. Clancy SA, Schacter DL, McNally RJ, Pitman RK. False recognition in women reporting recovered memories of sexual abuse. Psychol Sci. 2000;11:26-31.

24. Heaps C, Nash M. Individual differences in imagination inflation. Psychon Bull Rev. 1999;6:313-318.

25. Hyman IE, Billings FJ. Individual differences and the creation of false childhood memories. Memory. 1998;6:1-20.

26. Winograd E, Peluso JP, Glover TA. Individual differences in susceptibility to memory illusions. Appl Cogn Psychol. 1998;12:S5-S27.

27. Zhu B, Chen C, Loftus EF, et al. Individual differences in false memory from misinformation: cognitive factors. Memory. 2010;18:543-55.

28. Goodman GS, Ogle CM, Block SD, et al. False memory for traumarelated Deese-Roediger-McDermott lists in adolescents and adults with histories of child sexual abuse. Dev Psychopathol. 2011;23:423-438. 
29. Deese J. On the prediction of occurrence of particular verbal intrusions in immediate recall. J Exp Psychol. 1959;58:17-22.

30. Roediger III HL, McDermott KB. Creating false memories: remembering words not presented in lists. J Exp Psychol Learn Mem Cogn. 1995;21:803-814. 31. Gallo DA. Associative Illusions of Memory. New York, NY: Taylor \& Francis; 2006.

32. Gallo DA. False memories and fantastic beliefs: 15 years of the DRM illusion. Mem Cognit. 2010;38:833-848.

33. Posner MI, Keele SW. On the genesis of abstract ideas. J Exp Psychol. 1968:353-363.

34. Slotnick SD, Schacter DL. A sensory signature that distinguishes true from false memories. Nat Neurosci. 2004;7:664-672.

35. Koutstaal W, Schacter DL. Gist-based false recognition of pictures in older and younger adults. J Mem Lang. 1997;37:555-583.

36. Smith SM, Ward TB, Tindell DR, Sifonis CM, Wilkenfeld MJ. Category structure and created memories. Mem Cognit. 2000;28:386-95.

37. McClelland JL. Constructive memory and memory distortions: a parallel-distributed processing approach. In: Schacter DL, ed. Memory distortion: How Minds, Brains and Societies Reconstruct the Past. Cambridge, MA: Harvard University Press; 1995:69-90.

38. Reyna VF, Brainerd CJ. Fuzzy-trace theory: an interim synthesis. Learn Indiv Diff. 1995;7:1-75.

39. Koutstaal W, Verfaellie M, Schacter DL. Recognizing identical vs. similar categorically related common objects: further evidence for degraded gist-representations in amnesia. Neuropsychology. 2001;15:268-289.

40. Schacter DL, Verfaellie M, Pradere D. The neuropsychology of memory illusions: false recall and recognition in amnesic patients. J Mem Lang. 1996;35:319-334.

41. Verfaellie M, Schacter DL, Cook SP. The effect of retrieval instructions on false recognition: exploring the nature of the gist memory impairment in amnesia. Neuropsychologia. 2002;40:2360-2368.

42. Howe ML, Garner SR, Charlesworth M, Knott L. A brighter side to memory illusions: false memories prime children's and adults' insightbased problem solving. J Exp Child Psychol. 2011;108:383-393.

43. Dewhurst SA, Thorley C, Hammond ER, Ormerod TC. Convergent, but not divergent, thinking predicts susceptibility to associative memory illusions. Personal Indiv Diff. 2011;51:73-76.

44. Abe N, Okuda J, Suzuki M, et al. Neural correlates of true memory, false memory, and deception. Cereb Cortex. 2008;18:2811-2819.

45. Cabeza R, Rao S, Wagner AD, Mayer A, Schacter DL. Can medial temporal lobe regions distinguish true from false? An event-related fMRI study of veridical and illusory recognition memory. Proc Nat Acad Sci U S A. 2001;98:4805-4810. 46. Schacter DL, Reiman E, Curran T, et al. Neuroanatomical correlates of veridical and illusory recognition memory: evidence from positron emission tomography. Neuron. 1996;17:267-274.

47. Schacter DL, Buckner RL, Koutstaal W, Dale AM, Rosen BR. Late onset of anterior prefrontal activity during true and false recognition: an eventrelated fMRI study. Neuroimage. 1997;6:259-269.

48. Garoff-Eaton RJ, Slotnick SD, Schacter DL. Not all false memories are created equal: The neural basis of false recognition. Cereb Cortex. 2006; 16:1645-1652.

49. Kim H, Cabeza R. Differential contributions of prefrontal, medial temporal, and sensory-perceptual regions to true and false memory formation. Cereb Cortex. 2007;17:2143-50.

50. Kubota Y, Toichi M, Shimizu M, et al. Prefrontal hemodynamic activity predicts false memory--a near-infrared spectroscopy study. Neuroimage. 2006;31:1783-9.

51. Garoff RJ, Slotnick SD, Schacter DL. The neural origins of specific and general memory: The role of the fusiform cortex. Neuropsychologia. 2005;43:847-859.

52. Demb JB, Desmond JE, Wagner AD, Vaidya CJ, Glover GH, Gabrieli JDE. Semantic encoding and retrieval in the left inferior prefrontal cortex: a functional MRI study of task difficulty and process specificity. J Neurosci. 1995; 15:5870-5878.

53. Aminoff E, Schacter DL, Bar M. The cortical underpinnings of contextbased memory distortion. J Cogn Neurosci. 2008;20:2226-2237.

54. Bar M, Aminoff E. Cortical analysis of visual context. Neuron. 2003;38:347-358.
55. Bar M, Aminoff E, Schacter DL. Scenes unseen: the parahippocampal cortex intrinsically subserves contextual associations, not scenes or places per se. J Neurosci. 2008;28:8539-8544.

56. Bar M. The proactive brain: using analogies and associations to generate predictions. Trends Cogn Sci. 2007;11:280-289.

57. Garry M, Manning C, Loftus EF, Sherman SJ. Imagination inflation: imagining a childhood event inflates confidence that it occurred. Psychon Bull Rev. 1996;3:208-214.

58. Loftus EF. Make-believe memories. Am Psychol. 2003;58:867-873.

59. Loftus EF, Pickrell JE. The formation of false memories. Psychiatric Ann. 1995;25:720-725.

60. Gonsalves B, Paller KA. Neural events that underlie remembering something that never happened. Nat Neurosci. 2000;3:1316-1321.

61. Gonsalves B, Reber PJ, Gitelman DR, Parrish TB, Mesulam MM, Paller KA. Neural evidence that vivid imagining can lead to false remembering. Psychol Sci. 2004; 15:655-660.

62. Johnson MK, Raye CL. Reality monitoring. Psychol Rev. 1981;88:67-85. 63. Goff LM, Roediger HL, III. Imagination inflation for action events: repeated imaginings lead to illusory recollections. Mem Cognit. 1998;26:20-33.

64. Kensinger EA, Schacter DL. Neural processes underlying memory attribution on a reality-monitoring task. Cereb Cortex. 2006;16:1126-1133.

65. Addis DR, Wong AT, Schacter DL. Remembering the past and imagining the future: Common and distinct neural substrates during event construction and elaboration. Neuropsychologia. 2007;45:1363-1377.

66. Botzung A, Denkova E, Manning L. Experiencing past and future personal events: Functional neuroimaging evidence on the neural bases of mental time travel. Brain Cogn. 2008;66:202-212.

67. Okuda J, Fujii T, Ohtake $\mathrm{H}$, et al. Thinking of the future and the past: The roles of the frontal pole and the medial temporal lobes. Neuroimage. 2003; 19:1369-1380.

68. Hassabis D, Kumaran D, Maguire EA. Using imagination to understand the neural basis of episodic memory. J Neurosci. 2007;27:14365-14374.

69. Spreng RN, Grady CL. Patterns of brain activity supporting autobiographical memory, prospection, and theory of mind and their relationship to the default mode network. J Cogn Neurosci. 2010;22:1112-1123.

70. Szpunar KK, Watson JM, McDermott KB. Neural substrates of envisioning the future. Proc Natl Acad Sci U S A. 2007;104:642-647.

71. Addis DR, Wong AT, Schacter DL. Age-related changes in the episodic simulation of future events. Psychol Sci. 2008;19:33-41.

72. D'Argembeau A, Van der Linden M. Influence of emotion on memory for temporal information. Emotion. 2005;5:503-507.

73. D'Argembeau A, Van der Linden M. Individual differences in the phenomenology of mental time travel. Conscious Cogn. 2006;15:342-350.

74. Hassabis D, Kumaran D, Vann SD, Maguire EA. Patients with hippocampal amnesia cannot imagine new experiences. Proc Natl Acad Sci U S A. 2007;104:1726-1731.

75. Race E, Keane MM, Verfaellie M. Medial temporal lobe damage causes deficits in episodic memory and episodic future thinking not attributable to deficits in narrative construction. J Neurosci. 2011;31:10262-10269. 76. Spreng RN, Levine B. The temporal distribution of past and future autobiographical events across the lifespan. Mem Cognit. 2006;34:16441651.

77. Schacter DL, Addis DR, Buckner RL. Remembering the past to imagine the future: the prospective brain. Nat Rev Neurosci. 2007;8:657-661.

78. Schacter DL, Addis DR, Buckner RL. Episodic simulation of future events: Concepts, data, and applications. Ann N Y Acad Sci. 2008;1124:3960.

79. Suddendorf T, Corballis MC. The evolution of foresight: what is mental time travel and is it unique to humans? Behav Brain Sci. 2007;30:299313.

80. Buckner RL, Andrews-Hanna JR, Schacter DL. The brain's default network: anatomy, function, and relevance to disease. Ann N Y Acad Sci. 2008; 1124:1-38.

81. Spreng RN, Mar RA, Kim ASN. The common basis of autobiographical memory, prospection, navigation, theory of mind and the default mode: a quantitative meta-analysis. J Cogn Neurosci. 2009;32:489-510.

82. Eichenbaum H, Cohen NJ. From Conditioning to Conscious Recollection: Memory Systems of the Brain. New York, NY: Oxford University Press; 2001. 


\section{State of the art}

83. Addis DR, Cheng T, Roberts PR, Schacter DL. Hippocampal contributions to the episodic simulation of specific and general future events. Hippocampus. 2011;21:1045-1052.

84. Schacter DL, Addis DR. On the nature of medial temporal lobe contributions to the constructive simulation of future events. Philos Trans $R$ Soc $B$. 2009;364:1245-1253.

85. Addis DR, Schacter DL. Constructive episodic simulation: Temporal distance and detail of past and future events modulate hippocampal engagement. Hippocampus. 2008;18:227-237.

86. Addis DR, Pan L, Vu MA, Laiser N, Schacter DL. Constructive episodic simulation of the future and the past: distinct subsystems of a core brain network mediate imagining and remembering. Neuropsychologia. 2009;47:2222-2238.

87. Martin VC, Schacter DL, Corballis MC, Addis DR. A role for the hippocampus in encoding simulations of future events. Proc Natl Acad Sci U SA. 2011;108:13858-13863.

88. Ingvar DH. 'Memory of the future': an essay on the temporal organization of conscious awareness. Hum Neurobiol. 1985;4:127-136.

89. Murty VP, Ritchey M, Adcock RA, LaBar KS. fMRI studies of successful emotional memory encoding: a quantitative meta-analysis. Neuropsychologia. 2010;48:3459-3469.

90. Paller KA, Wagner AD. Observing the transformation of experience into memory. Trend Cogn Sci. 2002;6:93-102.

91. Szpunar KK, Addis DR, Schacter DL. Memory for emotional simulations: remembering a rosy future. Psychol Sci. 2012;23:24-29.

92. D'Argembeau A, Renaud O, Van der Linden M. Frequency, characteristics, and functions of future-oriented thoughts in daily life. App/ Cogn Psychol. 2011;35:96-103.

93. Kensinger EA. Remembering the details: effects of emotion. Emotion Rev. 2009;1:99-113.

94. Phelps EA. Emotion and cognition: insights from studies of the human amygdala. Annu Rev Psychol. 2006;57:27-53.

95. Walker WR, Skowronski JJ. The fading affect bias: but what the hell is it for? Appl Cogn Psychol. 2009;23:1122-1136.

96. King MJ, MacDougall AG, Ferris S, Herdman KA, McKinnon MC. Episodic simulation of future events is impaired in patients with major depressive disorder. Psychiatry Res. 2011;187:465-467.

97. Williams JM, Ellis NC, Tyers C, Healy H, Rose G, MacLeod AK. The specificity of autobiographical memory and imageability of the future. Mem Cognit. 1996;24:116-25.

98. MacLeod AK, Tata P, Kentish J, Carroll F, Hunter E. Anxiety, depression, and explanation-based pessimism for future positive and negative events. Clin Psychol Psychother. 1997;4:15-24.

99. Ruane D, MacLeod AK, Holmes EA. The simulation heuristic and visual imagery in pessimisim for negative events in anxiety. Clin Psychol Psychother. 2005;12:313-325.
100. Wheeler MA, Petersen SE, Buckner RL. Memory's echo: vivid recollection activates modality-specific cortex. Proc Nat Acad Sci U S A. 2000;97:11125-11129.

101.Schooler JW, Gerhard D, Loftus EF. Qualities of the unreal. J Exp Psychol Learn Mem Cognit. 1986;12:171-181.

102. Johnson MK, Foley MA, Suengas AG, Raye CL. Phenomenal characteristics of memories for perceived and imagined autobiographical events. $J$ Exp Psychol Gen. 1988;117:371-376.

103. Marche TA, Brainerd CJ, Reyna VF. Distinguishing true from false memories in forensic contexts: can phenomenology tell us what is real? Appl Cogn Psychol. 2010;24:1168-1182.

104. Mather M, Henkel LA, Johnson MK. Evaluating characteristics of false memories: Remember/know judgments and memory characteristics questionnaire compared. Mem Cognit. 1997;25:826-837.

105. Norman KA, Schacter DL. False recognition in young and older adults: exploring the characteristics of illusory memories. Mem Cognit. 1997:25:838-848.

106. Johnson MK, Nolde SF, Mather M, Kounios J, Schacter DL, Curran T. The similarity of brain activity associated with true and false recognition memory depends on test format. Psychol Sci. 1997;8:250-257.

107. Okado Y, Stark C. Neural activity during encoding predicts false memories created by misinformation. Learn Mem. 2005;12:3-11.

108. Stark C, Okado Y, Loftus EF. Imaging the reconstruction of true and false memories using sensory reactivation and the misinformation paradigms. Learn Mem. 2010;17:485-488.

109. Fabiani M, Stadler MA, Wessels PM. True but not false memories produce a sensory signature in human lateralized brain potentials. J Cogn Neurosci. 2000;12:941-949.

110. Loftus EF, Davis D. Recovered memories. Annu Rev Clin Psychol. 2006;2:469-498.

111. McNally RJ, Geraerts E. A new solution to the recovered memories debate. Perspect Psychol Sci. 2009;4:126-134.

112. Hyman IE, Jr., Pentland J. The role of mental imagery in the creation of false childhood memories. J Mem Lang. 1996;35:101-117.

113. Bernstein DM, Loftus EF. How to tell if a particular memory is true or false. Perspect Psychol Sci. 2009;4:370-374.

114. Rissman J, Greely HT, Wagner AD. Detecting individual memories through the neural decoding of memory states and past experience. Proc Natl Acad Sci U S A. 2010;107:9849-9854.

115. Schacter DL, Chamberlain JP, Gaesser B, Gerlach KD. Neuroimaging of true, false, and imaginary memories: findings and implications. In: Nadel L, Sinnott-Armstrong W, eds. Memory and Law. New York, NY: Oxford University Press. In press.

116. Buda M, Fornito A, Bergstrom ZM, Simons JS. A specific brain structural basis for individual differences in reality monitoring. J Neurosci. 2011;31:14308-14313. 